\title{
Remote sensing of aerosols over snow using infrared AATSR observations
}

\author{
L. G. Istomina ${ }^{1}$, W. von Hoyningen-Huene ${ }^{1}$, A. A. Kokhanovsky ${ }^{1}$, E. Schultz ${ }^{2}$, and J. P. Burrows ${ }^{1}$ \\ ${ }^{1}$ Institute of Environmental Physics, University of Bremen, Bremen, Germany \\ ${ }^{2}$ Institute of Mineralogy and Geochemistry, KIT Karlsruhe, Germany
}

Received: 22 November 2010 - Published in Atmos. Meas. Tech. Discuss.: 10 January 2011

Revised: 29 April 2011 - Accepted: 17 May 2011 - Published: 17 June 2011

\begin{abstract}
Infrared (IR) retrievals of aerosol optical thickness (AOT) are challenging because of the low reflectance of aerosol layer at longer wavelengths. In this paper we present a closer analysis of this problem, performed with radiative transfer (RT) simulations for coarse and accumulation mode of four main aerosol components. It shows the strong angular dependence of aerosol IR reflectance at low solar elevations resulting from the significant asymmetry of aerosol phase function at these wavelengths. This results in detectable values of aerosol IR reflectance at certain non-nadir observation angles providing the advantage of multiangle remote sensing instruments for a retrieval of AOT at longer wavelengths. Such retrievals can be of importance e.g. in case of a very strong effect of the surface on the top of atmosphere (TOA) reflectance in the visible spectral range. In the current work, a new method to retrieve AOT of the coarse and accumulation mode particles over snow has been developed using the measurements of Advanced Along Track Scanning Radiometer (AATSR) on board the ENVISAT satellite. The algorithm uses AATSR channel at $3.7 \mu \mathrm{m}$ and utilizes its dual-viewing observation technique, implying the forward view with an observation zenith angle of around 55 degrees and the nadir view. It includes cloud/snow discrimination, extraction of the atmospheric reflectance out of measured brightness temperature (BT) at $3.7 \mu \mathrm{m}$, and interpolation of look-up tables (LUTs) for a given aerosol reflectance. The algorithm uses LUTs, separately simulated with RT forward calculations. The resulting AOT at $500 \mathrm{~nm}$ is estimated from the value at $3.7 \mu \mathrm{m}$ using a fixed Angström parameter.
\end{abstract}

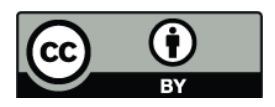

Correspondence to: L. G. Istomina (lora@iup.physik.uni-bremen.de)
The presented method has been validated against groundbased Aerosol Robotic Network (AERONET) data for 4 high Arctic stations and shows good agreement.

A case study has been performed at W-Greenland on 5 July 2008. The day before was characterized by a noticeable dust event. The retrieved AOT maps of the region show a clear increase of AOT in the Kangerlussuaq area. The area of increased AOT was detected on 5 July on the ice sheet east of Kangelussuaq, opposite to the observed north easterly wind at ground level. This position can be explained by a small scale atmospheric circulation transporting the mobilized mineral dust upslope, after its intrusion into the upper branch of the circulation.

The performed study of atmospheric reflectance at $3.7 \mu \mathrm{m}$ also shows possibilities for the detection and retrievals of cloud properties over snow surfaces.

\section{Introduction}

The large surface spectral reflectance poses significant challenges for the retrieval of AOT above snow from observations of the upwelling back scattered radiation at the top of the atmosphere in the visible spectral range. At the same time, satellite retrievals of AOT over snow are necessary to assess and understand the role of aerosol at high latitudes. Aerosols affect energy balance of the Polar Regions in many ways, both on local and global scale (Tomasi et al., 2007). The impact of aerosol particles on climate is considered to be one of the largest uncertainties in climate modeling. One of the main reasons for this uncertainty is the lack of data on global scale, especially in the Polar Regions. Ground based measurements with significant temporal coverage are only

Published by Copernicus Publications on behalf of the European Geosciences Union. 
available at a few locations either at the North or the South Poles. In order to resolve the uncertainty of aerosol amount, transport and influence on climate, significant temporal and spatial coverage is needed. This can only be achieved using active or passive measurements made from orbiting platforms.

The fraction of the radiation being reflected from a snow surface in the observed TOA reflectance at visible wavelengths is large due to the large spectral reflectance of snow surfaces and the relatively low atmospheric reflectance. In addition a wide variety of snow types and temporal evolution of snow properties cause variation of snow bidirectional reflection function (BRDF). Attempts to remove this large unknown surface effect from the TOA reflectance by using an assumed snow model, lead to strong surface contamination of resulting AOT (Istomina et al., 2009), because the assumed surface model cannot account for the existing BRDF variability. Better results can be achieved by using the advantage of multiangle observations (Istomina et al., 2010a) in order to reduce at least the effect of snow surface spectral reflectance on the TOA reflectance. However, the variable BRDF shape of snow still causes offsets in AOT retrieved on global scale.

Spangenberg et al. (2001) discussed the influence of infrared atmospheric reflectance onto AATSR brightness temperature (BT) at $3.7 \mu \mathrm{m}$ with respect to the problem of cloud detection over snow. This idea has been successfully applied for cloud screening over snow using AATSR channel at $3.7 \mu \mathrm{m}$ in combination with other AATSR channels (Istomina et al., 2010b). We use this cloud screening approach in this work, too (see Sect. 4.1). Good infrared calibration of the AATSR instrument (Smith et al., 2001) provides the possibility of applying the same approach also to aerosol layers. This paper describes a new retrieval approach to determine AOT over snow. The following sections of this work address the analysis of snow and aerosol infrared properties (Sects. 2 and 3 ), a description of the recently developed aerosol retrieval algorithm at $3.7 \mu \mathrm{m}$ (Sect. 4) and its validation by comparison with AERONET measurements (Sect. 5).

\section{Infrared scattering characteristics of snow surface}

Thermal properties of snow have been measured (Hori et al., 2006; English et al., 1995) and show that due to its density snow is very close to a black body which emits according its physical temperature. Wald (1994) showed that the reflection of snow is very low in the whole IR range of AATSR (at 3.7, 10.8 and $12 \mu \mathrm{m}$ ). This is also confirmed by e.g. snow emissivity measurements in MODIS USCB Emissivity Library. Measured emissivity is quite stable throughout the thermal region of the spectrum (variation around $2 \%$ ). Hori et al. (2006) show that emissivity of snow for a given temperature depends on its physical parameters such as grain size and liquid water content. However, these dependencies cause a variation of snow emissivity of less than $5 \%$ (Rees, 2006). Therefore in the current work we neglect possible temporal and spatial variability of snow emissivity. In further sections, however, we show how to account for possible inaccuracies of this approach, by using AATSR nadir view reflectance at $3.7 \mu \mathrm{m}$ (see e.g. Sect. 4.2).

\section{Infrared scattering characteristics of atmospheric aerosols depending on the particle size}

In order to study the behavior of aerosol scattering characteristics depending on size distribution and wavelength we have calculated aerosol phase functions and single scattering albedo for spherical polydisperse particles with the refractive indices corresponding to four main aerosol components (water soluble, oceanic, soot, mineral dust) for two wavelengths $-550 \mathrm{~nm}$ and $3.7 \mu \mathrm{m}$. We used the Lorenz-Mie theory (De Rooij and Van Der Stap, 1984; Mishchenko et al., 1999) and lognormal size distribution (Eq. 1).

$n(r)=$ const $\times r^{-1} \exp \left[-\frac{\left(\ln r-\ln r_{\mathrm{g}}\right)^{2}}{2 \ln ^{2} \sigma_{\mathrm{g}}}\right]$

where const is chosen in such a way that $\int_{0}^{\infty} n(r) d r=1$.

According to Twomey (1997), the scattering behavior of an aerosol load in the IR spectral region is dominated by the larger particles, even if they are a few, as smaller particles are not effective scatterers at these wavelengths, therefore in current study only accumulation and coarse mode particles are taken into account. Though accumulation mode is generally referred to as fine mode, e.g. Hobbs (1993) states that accumulation mode particles of polar aerosol are larger than accumulation mode particles of other aerosol types (mean particle radius of around $0.4 \mu \mathrm{m}$ as compared to around $0.1 \mu \mathrm{m}$ or less for background, maritime, rural, urban, desert dust and continental aerosol types). This made it possible to include also accumulation mode into the study along with the coarse mode. Smaller particles (nucleation and Aitken modes) were not taken into account in this study due to their low scattering efficiency at the wavelength of the retrieval.

To represent coarse and accumulation mode particles, we took the geometric standard deviation $\sigma$ which has been measured during an Arctic smoke event (Treffeisen et al., 2007), $\ln ^{2} \sigma_{\mathrm{g}}=0.22$, and average size parameters of $r_{\mathrm{g}}=1.7 \mu \mathrm{m}$ for the coarse mode, and $r_{\mathrm{g}}=0.5 \mu \mathrm{m}$ for the accumulation mode, with the effective radius equal to $2.9 \mu \mathrm{m}$ for the coarse mode and $0.64 \mu \mathrm{m}$ for the accumulation mode.

The result of the phase function calculation is shown in Fig. 1 for the coarse mode and in Fig. 2 for the accumulation mode. The refractive indices (Kokhanovsky, 2004) and calculated single scattering albedo are shown in Table 1 for $550 \mathrm{~nm}$ and in Table 2 for $3.7 \mu \mathrm{m}$.

It is readily visible that phase functions of water soluble, oceanic and dust aerosol components of both sizes show significant back- and forward scattering details at $550 \mathrm{~nm}$, but 


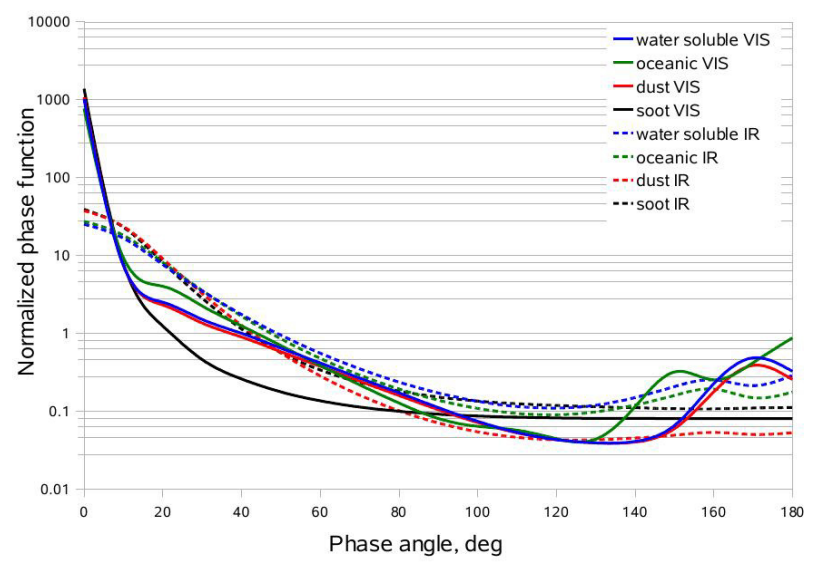

Fig. 1. Phase functions for coarse mode of oceanic, water soluble, dust and soot aerosol components calculated for spherical polydisperse particle at $550 \mathrm{~nm}$ (VIS, continuous line in the figure) and $3.7 \mu \mathrm{m}$ (IR, dashed line in the figure). The phase functions are normalized to unity, see SSA in text.

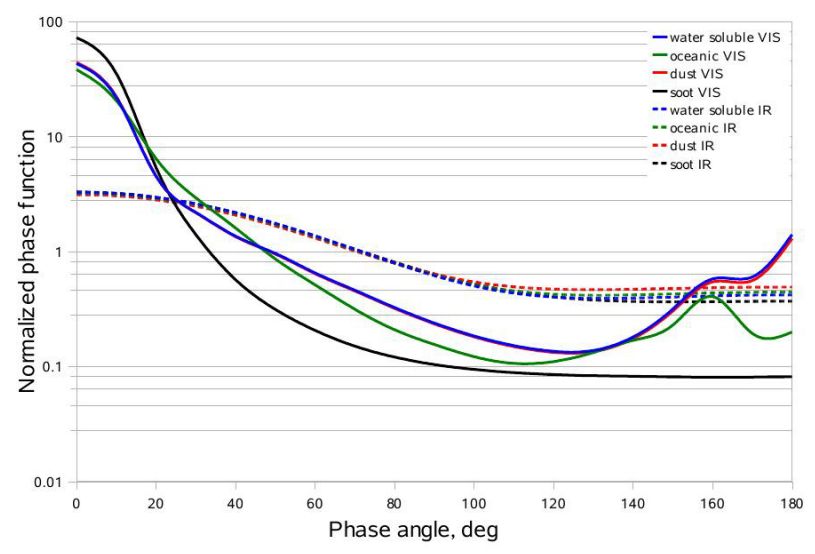

Fig. 2. Phase functions for accumulation mode of oceanic, water soluble, dust and soot aerosol components calculated spherical polydisperse particles at $550 \mathrm{~nm}$ (VIS, continuous line in the figure) and $3.7 \mu \mathrm{m}$ (IR, dashed line in the figure). The phase functions are normalized to unity, see SSA in text.

the forward scattering peak of accumulation mode is weaker than that of coarse mode by approximately one order of magnitude. The magnitude of backscattering details is very similar for both particle sizes. For the coarse mode, the overall asymmetry of the phase functions at $3.7 \mu \mathrm{m}$ and $550 \mathrm{~nm}$ is very similar, with the exception of soot component, which shows a slightly lower asymmetry at phase angles larger than 20 degrees in comparison to the other components. The forward scattering peaks, however, are similar.

For the accumulation mode, the asymmetry of all the phase functions at $550 \mathrm{~nm}$ is clearly larger in comparison to the asymmetry at $3.7 \mu \mathrm{m}$.
Table 1. SSA, real $n$ and imaginary $\chi$ part of the refractive index for coarse and accumulation mode of water soluble, oceanic, dust and soot aerosol components at $550 \mathrm{~nm}$.

\begin{tabular}{lccccc}
\hline \multirow{2}{*}{$\begin{array}{l}\text { Aerosol } \\
\text { component }\end{array}$} & \multicolumn{2}{c}{ Refractive index } & & \multicolumn{2}{c}{ SSA } \\
\cline { 2 - 3 } \cline { 5 - 6 } & $n$ & $\chi$ & & $\begin{array}{c}\text { Coarse } \\
\text { mode }\end{array}$ & $\begin{array}{c}\text { Accumulation } \\
\text { mode }\end{array}$ \\
\hline Water soluble & 1.530 & $6.00 \mathrm{E}-03$ & & 0.75 & 0.92 \\
Oceanic & 1.381 & $4.26 \mathrm{E}-09$ & & 1.00 & 1.00 \\
Dust & 1.530 & $8.00 \mathrm{E}-03$ & & 0.71 & 0.89 \\
Soot & 1.750 & $4.40 \mathrm{E}-01$ & & 0.55 & 0.50 \\
\hline
\end{tabular}

Table 2. SSA, real $n$ and imaginary $\chi$ part of the refractive index for coarse and accumulation mode of water soluble, oceanic, dust and soot aerosol components at $3.7 \mu \mathrm{m}$.

\begin{tabular}{lccccc}
\hline \multirow{2}{*}{$\begin{array}{l}\text { Aerosol } \\
\text { component }\end{array}$} & \multicolumn{2}{c}{ Refractive index } & & \multicolumn{2}{c}{ SSA } \\
\cline { 2 - 3 } \cline { 5 - 6 } & $n$ & $\chi$ & & $\begin{array}{c}\text { Coarse } \\
\text { mode }\end{array}$ & $\begin{array}{c}\text { Accumulation } \\
\text { mode }\end{array}$ \\
\hline Water soluble & 1.452 & $4.00 \mathrm{E}-03$ & & 0.97 & 0.96 \\
Oceanic & 1.398 & $2.90 \mathrm{E}-03$ & & 0.97 & 0.96 \\
Dust & 1.270 & $1.10 \mathrm{E}-02$ & & 0.91 & 0.74 \\
Soot & 1.900 & $5.7 \mathrm{E}-01$ & & 0.49 & 0.38 \\
\hline
\end{tabular}

To study the influence of these phase function details on the angular reflectance with respect to wavelength change, we performed RT simulations. For this purpose we used the forward RT model SCIATRAN developed at the University of Bremen (Rozanov et al., 2005). The TOA reflectance (the height of the TOA is equal to $60 \mathrm{~km}$ ) over black Lambertian surface for accumulation and coarse modes of dust aerosol component at $550 \mathrm{~nm}$ and $3.7 \mu \mathrm{m}$ for aerosol optical thickness 0.1 at $550 \mathrm{~nm}$ was calculated. The aerosol was confined to the troposphere and represented as a uniform layer in the range of heights from 0 to $3 \mathrm{~km}$ above the surface. We assume no stratospheric aerosols, no Rayleigh scattering, no gas absorption, the pressure and temperature profiles were taken for July at the $75^{\circ} \mathrm{N}$, with the temperature at the surface being $280 \mathrm{~K}$ and standard pressure. The number of discretized zenith angles (streams) was taken 16, the number of Legendre moments used to expand the scattering phase functions into the Legendre series was equal to 35 and truncated for delta-M approximation to 34 .

The result is shown in Fig. 3 for coarse mode and in Fig. 4 for accumulation mode.

For the given AOT $=0.1$ at $550 \mathrm{~nm}$ the reflectance patterns are similar for both sizes and wavelengths, showing decreased reflectance around nadir and corresponding increase in the forward and backscattering directions at $550 \mathrm{~nm}$. The backscattering peak is absent at $3.7 \mu \mathrm{m}$, which corresponds 


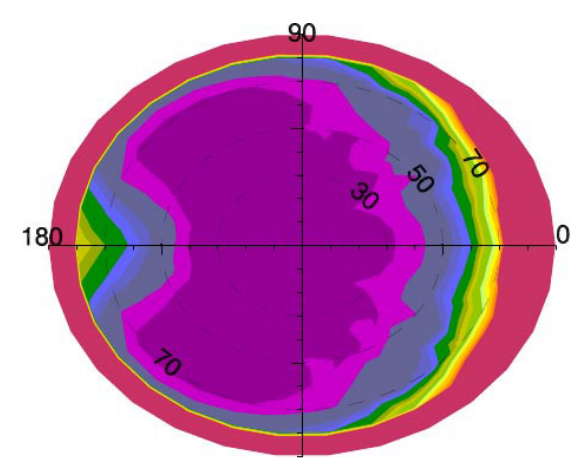

TOA reflectance, $\%$

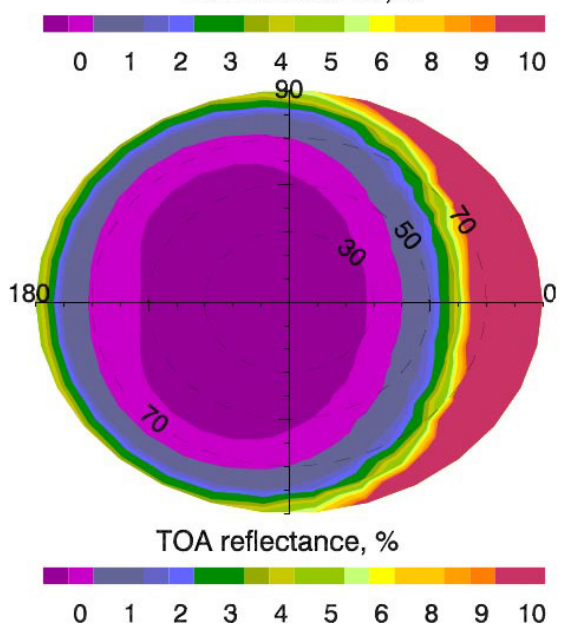

Fig. 3. Angular behavior of aerosol reflectance for coarse mode of dust aerosol component $550 \mathrm{~nm}$ (upper panel) and at $3.7 \mu \mathrm{m}$ (lower panel). Sun zenith angle is equal to 65 degrees, $\mathrm{AOT}=0.1$.

to the shape of phase functions discussed above. The expected extreme spectral decrease of reflectance is visible for accumulation mode, in contrast to relatively unchanged magnitudes of reflectance of the coarse mode. It is very important to notice that even for the accumulation mode the magnitude of IR reflectance in the upper forward quarter-sphere (azimuth angle less than 90 degrees) is of the same order as that at $550 \mathrm{~nm}$, nadir view. This makes it possible for the IR retrieval to employ the TOA reflectance values of same magnitude as at $550 \mathrm{~nm}$, nadir, by simply using forward view within certain azimuth angles. For the coarse mode the situation is even better: no change of reflectance magnitude being observed at $3.7 \mu \mathrm{m}$ as compared to $550 \mathrm{~nm}$.

The comparison of the SSA values for different aerosol modes and components (Tables 1 and 2) along with the similarity of the IR phase functions shapes (Figs. 1 and 2) implies that all possible differences in the IR TOA reflectance appearing with the change of aerosol type would be mainly caused by the corresponding SSA change and the shape of the IR TOA reflectance will not be affected. This makes it possible to apply the proposed usage of the satellite forward view for various aerosol types.
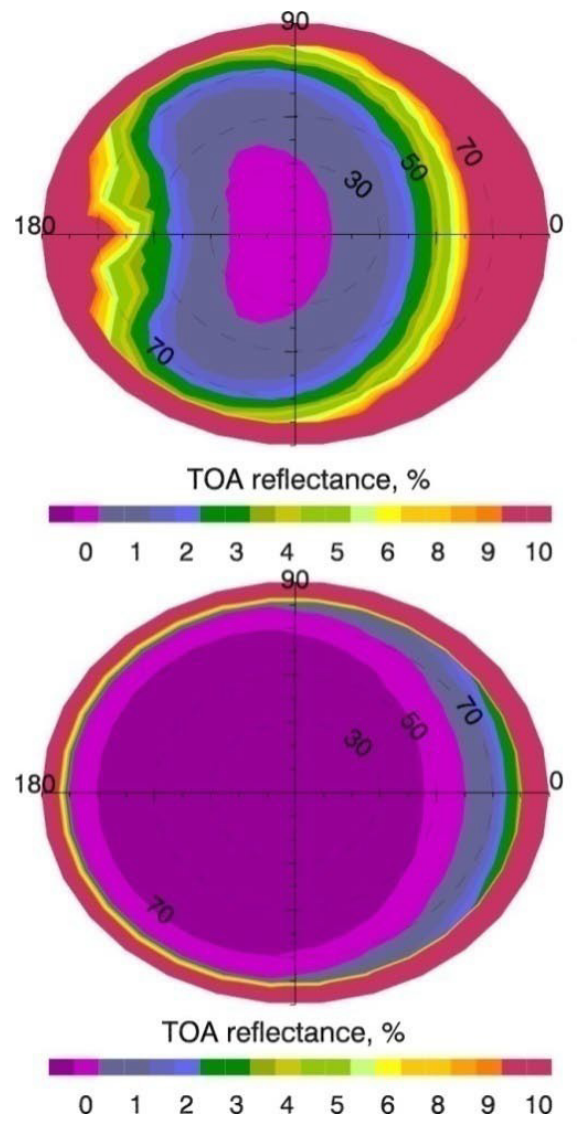

Fig. 4. Angular behavior of aerosol reflectance for accumulation mode of dust aerosol component $550 \mathrm{~nm}$ (upper panel) and at $3.7 \mu \mathrm{m}$ (lower panel). Sun zenith angle is equal to 65 degrees, $\mathrm{AOT}=0.1$.

\section{Aerosol optical thickness retrieval scheme}

As it can be seen in the previous sections, the task of AOT retrieval over snow at $3.7 \mu \mathrm{m}$ very much resembles the standard task of aerosol retrieval over dark surface in the visible range of spectrum. Some peculiarities, however, still exist. Some of them simplify the task, as e.g. the negligible effect of Rayleigh scattering and, correspondingly, the surface elevation at $3.7 \mu \mathrm{m}$, while others are more challenging, e.g. the accurate extraction of atmospheric reflectance from the measured AATSR BT at $3.7 \mu \mathrm{m}$. The theoretical background and the details of LUT calculations are described in the further 3 subsections. Although current work is dedicated to aerosol retrieval, the discussed approach can also be used for the detection and retrieval of cloud properties over snow, providing an advantageous alternative to existing cloud screening methods over snow.

\subsection{Snow/cloud discrimination}

The cloud/snow discrimination was performed as introduced in Istomina et al. (2010b). 
It uses a combination of relative thresholds in seven AATSR channels in order to discriminate the spectral behavior of clear snow scene from that of cloud, land, ocean, etc. These criteria connect nadir top of atmosphere reflectances in visible (Eqs. 5 and 6), near-infrared (Eq. 4) and brightness temperatures in thermal infrared (Eqs. 2 and 3) regions of spectrum.

$$
\begin{aligned}
& \left|\frac{\mathrm{BT}(3.7 \mu \mathrm{m})-\mathrm{BT}(10.8 \mu \mathrm{m})}{\mathrm{BT}(3.7 \mu \mathrm{m})}\right|<3 \% \\
& \left|\frac{\mathrm{BT}(3.7 \mu \mathrm{m})-\mathrm{BT}(12 \mu \mathrm{m})}{\mathrm{BT}(3.7 \mu \mathrm{m})}\right|<3 \% \\
& \frac{R_{\mathrm{TOA}}(0.87 \mu \mathrm{m})-R_{\mathrm{TOA}}(1.6 \mu \mathrm{m})}{R_{\mathrm{TOA}}(0.87 \mu \mathrm{m})}>80 \% \\
& \frac{R_{\mathrm{TOA}}(0.87 \mu \mathrm{m})-R_{\mathrm{TOA}}(0.66 \mu \mathrm{m})}{R_{\mathrm{TOA}}(0.87 \mu \mathrm{m})}<10 \% \\
& \left|\frac{R_{\mathrm{TOA}}(0.66 \mu \mathrm{m})-R_{\mathrm{TOA}}(0.55 \mu \mathrm{m})}{R_{\mathrm{TOA}}(0.66 \mu \mathrm{m})}\right|<40 \%
\end{aligned}
$$

While the visible (VIS) and near-infrared (NIR) criteria (Eqs. 4, 5 and 6) select scenes with the spectral behavior similar to snow spectrum, the thermal infrared (TIR) thresholds (Eqs. 2 and 3) distinguish cloud free areas over surfaces with emissivity close to unity (snow, open ocean). The combination of both VIS/NIR and TIR criteria makes it possible to distinguish various states of the system "surface + atmosphere". For example, cloud free case would correspond to conditions (Eqs. 2 and 3) being true, due to the absence of "stray" cloud reflectance at $3.7 \mu \mathrm{m}$. Conversely, if the TIR criteria (Eqs. 2 and 3) are false, there is a non black body present in the scene - either a cloud, or e. g. bare soil area. True VIS (Eqs. 5 and 6) and NIR criteria (Eq. 4) mean that the observed spectrum is close to a snow spectrum, which could mean snow, ice cloud, or thin water cloud over snow as well. If at least one of VIS/NIR criteria is false, there is a possibility of either a thick water cloud with the NIR (Eq. 4) criterion failing, or surface which a spectrum different from that of snow (e.g. ocean, bare soil, vegetation, etc).

\subsection{Theoretical basis of aerosol optical thickness retrieval in the infrared}

It is known that AATSR brightness temperature (BT) product measured at $3.7 \mu \mathrm{m}$ is contaminated by atmospheric reflectance. Spangenberg et al. (2001) suggested a way to remove this contamination and extract reflectance $\rho_{\text {atm }}\left(3.7, \mu_{0}, \mu, \phi\right)$ from the BT. This approach has been initially meant to be used for cloud/snow discrimination, as snow surface at a given wavelength is an almost perfect black body and does not reflect, whereas clouds (even thin cirrus) do have reflective properties. Like clouds, aerosol layers also cannot be considered to be black bodies, so their reflectance at $3.7 \mu \mathrm{m}$ is not zero. The magnitude of this effect is much lower than that of clouds, however, good calibration of IR channels of AATSR (better than 0.1 Kelvin according to Smith et al., 2001) makes it possible to use this effect for AOT retrieval.

In order to utilize lookup table approach to make the inversion and retrieve AOT, we need to express the measured top of atmosphere radiances analytically. Let us use reflectances $\rho$ rather than radiances $I$ :

$\rho=\frac{\pi I}{\mu_{0} f}$

where $f$ is the solar flux at the top of the atmosphere, and $\theta_{0}=\arccos \mu_{0}$ is the solar zenith angle.

Assuming that the atmosphere and aerosol load are horizontally uniform and have a total optical thickness $\tau$, and underlying surface is Lambertian, one can write the well-known expression:

$$
\begin{aligned}
\rho_{\mathrm{TOA}}\left(\lambda, \mu_{0}, \mu, \phi\right)= & \rho_{\mathrm{atm}}\left(\lambda, \mu_{0}, \mu, \phi\right) \\
& +\frac{\rho_{\mathrm{sfc}}(\lambda) \cdot T_{1}\left(\lambda, \mu_{0}\right) T_{2}(\lambda, \mu)}{1-\rho_{\mathrm{sfc}}(\lambda) \cdot s(\lambda)}
\end{aligned}
$$

where $\theta=\arccos \mu$ is the observation zenith angle, $\varphi$ is the relative azimuth angle, $\rho_{\mathrm{TOA}}\left(\lambda, \mu_{0}, \mu, \phi\right)$ is the total reflectance of the system "surface + atmosphere", $\rho_{\text {atm }}\left(\lambda, \mu_{0}, \mu, \phi\right)$ is the atmospheric reflectance (the reflectance of the aerosol, Rayleigh scattering, ozone absorption), $s(\lambda)$ is the atmospheric hemispherical albedo, $T_{1}\left(\lambda, \mu_{0}\right)=E\left(\mu_{0}\right)+\exp \left(-\tau / \mu_{0}\right)$ is the atmospheric transmittance from the top-of-atmosphere to the surface, $T_{2}(\lambda, \mu)=E(\mu)+\exp (-\tau / \mu)$ is the total atmospheric transmittance from the surface to a receiver (e.g., placed on a satellite), $E\left(\mu_{0}\right)$ and $E(\mu)$ are diffuse transmittances from top-of-atmosphere to the surface and from the surface to the receiver respectively, $\exp \left(-\tau / \mu_{0}\right)$ and $\exp (-\tau / \mu)$ are the direct transmittances from top-of-atmosphere to the surface and from the surface to the receiver respectively, $\rho_{\text {sfc }}(\lambda)$ is the Lambertian reflectance of the surface.

Of course, Eq. (8) is still valid at $3.7 \mu \mathrm{m}$ and can be written as:

$\rho_{\mathrm{TOA}}\left(3.7, \mu_{0}, \mu, \phi\right)=\rho_{\mathrm{aer}}\left(3.7, \mu_{0}, \mu, \phi\right)+\rho_{\mathrm{sfc}}(3.7)$

where $\rho_{\mathrm{TOA}}\left(3.7, \mu_{0}, \mu, \phi\right)$ is the calculated reflectance of the system "surface + atmosphere" at $3.7 \mu \mathrm{m}, \rho_{\text {aer }}\left(3.7, \mu_{0}, \mu, \phi\right)$ is the aerosol reflectance at $3.7 \mu \mathrm{m}$ (interpolated from LUT). Here we neglect Rayleigh scattering and multiple scattering between the surface and the atmosphere, and assume that AOT is very small.

To estimate $\rho_{\mathrm{TOA}}\left(3.7, \mu_{0}, \mu, \phi\right)$ from BT $(3.7 \mu \mathrm{m})$, we invert the Planck function in order to find the temperature corresponding to the radiance measurement at $3.7 \mu \mathrm{m}$ and extract the reflectance part of it. This method used by Allen et al. (1990), Trepte et al. (1999), Spangenberg et al. (2001). 
The radiance measured at $3.7 \mu \mathrm{m}$ can be expressed as following:

$$
\begin{aligned}
L_{3.7 \mu \mathrm{m}}= & \varepsilon_{3.7 \mu \mathrm{m}} \cdot B_{3.7 \mu \mathrm{m}}\left(T_{\mathrm{surf}}\right) \\
& +\rho_{\mathrm{TOA}}\left(3.7, \mu_{0}, \mu, \phi\right) L_{0} \mu_{0}
\end{aligned}
$$

where $\varepsilon_{3.7 \mu \mathrm{m}}$ is the surface emittance at $3.7 \mu \mathrm{m}$, $B_{3.7 \mu m}\left(T_{\text {surf }}\right)$ is the Planck function at $3.7 \mu \mathrm{m}$ for the surface temperature, which is approximated by measured BT at $12 \mu \mathrm{m}$. $L_{0}$ is the incident solar radiance at $3.7 \mu \mathrm{m}$.

The first term of right hand side of Eq. (10) is the contribution to the measured radiance from the thermal emission of the surface assuming the transmittance of the atmosphere to be equal to 1 . The second term on the right hand side is the contribution to the measured radiance due to the solar reflection. The amount of the reflected solar radiance reaching the satellite is determined by the incident solar radiance $L_{0}$ weighted by the cosine of the solar zenith angle $\mu_{0}$ and the bidirectional reflectance of the surface and the atmosphere $\rho_{\mathrm{TOA}}\left(3.7, \mu_{0}, \mu, \phi\right)$.

Using Eq. (10), we can write:

$\rho_{\mathrm{TOA}}\left(3.7, \mu_{0}, \mu, \phi\right)=\frac{B_{3.7 \mu \mathrm{m}}\left(T_{3.7 \mu \mathrm{m}}\right)-\varepsilon_{3.7 \mu \mathrm{m}} \cdot B_{3.7 \mu \mathrm{m}}\left(T_{12 \mu \mathrm{m}}\right)}{\mu_{0} \cdot S_{3.7 \mu \mathrm{m}}}$

where $T_{3.7 \mu \mathrm{m}}$ is the measured $3.7 \mu \mathrm{m}$ brightness temperature, $T_{12 \mu \mathrm{m}}$ is the measured $12 \mu \mathrm{m}$ brightness temperature, $\mu_{0}$ is the cosine of solar zenith angle, $S_{3.7 \mu \mathrm{m}}$ is the solar constant at $3.7 \mu \mathrm{m}\left(3.47 \mathrm{Wm}^{-2} \mu \mathrm{m}^{-1}\right), \varepsilon_{3.7 \mu \mathrm{m}}$ is the clear snow emittance, $B_{3.7 \mu \mathrm{m}}(\mathrm{BT})$ is the Planck function at $3.7 \mu \mathrm{m}$ for some temperature BT.

It is important to note that in case of surface being a perfect black body, the term $\rho_{\text {sfc }}(3.7)$ in Eq. (9) is equal to zero. However, snow emissivity $\varepsilon_{3.7 \mu \mathrm{m}}$ may be not constant throughout the scene, therefore surface contamination can be still possible and is included in Eq. (9). As can be seen from Figs. 3 and 4, aerosol reflectance in the nadir direction is negligibly small. Within this assumption, relatively high nadir values of calculated $\rho_{\mathrm{TOA}}\left(3.7, \mu_{0}, 0, \phi\right)$ would mean that emissivity $\varepsilon_{3.7 \mu \mathrm{m}}$ used in the calculation is different from the real emissivity of the scene, and $\rho_{\mathrm{TOA}}\left(3.7, \mu_{0}, 0, \phi\right)$ is nothing but the surface contamination which needs to be subtracted from the forward TOA reflectance $\rho_{\mathrm{TOA}}\left(3.7, \mu_{0}, 55, \phi\right)$ in order to get the forward aerosol reflectance $\rho_{a e r}\left(3.7, \mu_{0}, 55, \phi\right)$.

Within the assumption of no angular variability of snow emissivity, we can get the surface-free aerosol reflectance:

$$
\begin{aligned}
\rho_{\text {aer }}\left(3.7, \mu_{0}, 55, \phi\right)= & \rho_{\mathrm{TOA}}\left(3.7, \mu_{0}, 55, \phi\right) \\
& -\rho_{\mathrm{TOA}}\left(3.7, \mu_{0}, 0, \phi\right)
\end{aligned}
$$

This $\rho_{\text {aer }}\left(3.7, \mu_{0}, 55, \phi\right)$ is used for the LUT interpolation (Sect. 4.3).

Our particular case of low sun angles requires careful accounting for airmasses, different from that usual to planeparallel atmosphere model. For RT calculations of LUTs, we

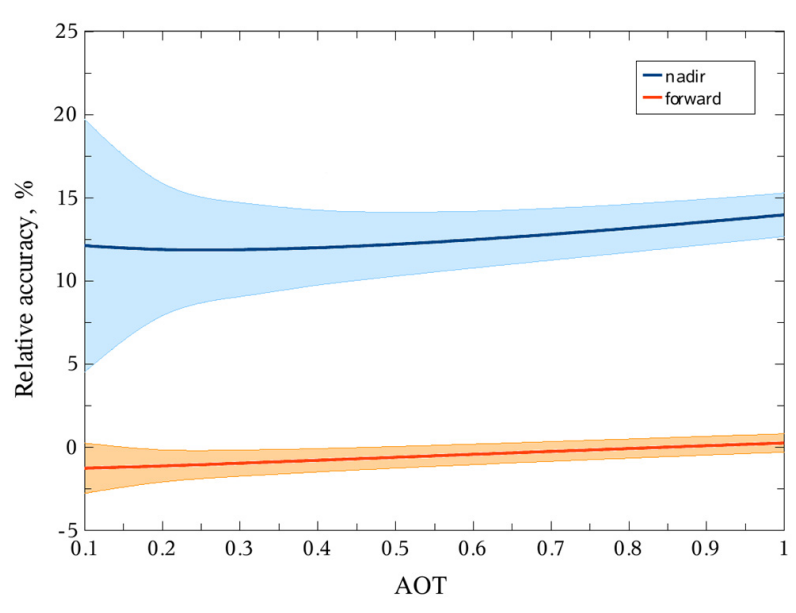

Fig. 5. Relative error of TOA reflectance reconstructed from the BT at $12 \mu \mathrm{m}$ and $3.7 \mu \mathrm{m}$ for the forward (red curve) and nadir (blue curve) views. Filled areas show the sensitivity of the TOA reflectance at $3.7 \mu \mathrm{m}$ to the AATSR calibration error of $\pm 0.1 \mathrm{~K}$.

use pseudospherical model of the atmosphere. The pseudospherical mode of SCIATRAN is calculating the light paths for the direct solar beam in a spherical atmosphere, and then solves the plane-parallel RT equation. To correct AATSR measured quantities, we use approximation described in Kasten, Young (1989). To perform the comparison of the retrieved AOTs to the ground based measurements, we bring all the AOTs at $3.7 \mu \mathrm{m}$ to $500 \mathrm{~nm}$ using a fixed Angström parameter equal to 1.0 .

In order to check the performance of Eqs. (10) and (11), we performed RT simulations with the forward model SCIATRAN. For this we simulated $3.7 \mu \mathrm{m}$ and $11 \mu \mathrm{m}$ brightness temperatures for both nadir and forward views for a surface with the temperature $263 \mathrm{~K}$ and atmosphere with the AOT from 0 to 1 at $550 \mathrm{~nm}$. The illumination angle is equal to $65^{\circ}$, observation angles are $0^{\circ}$ and $55^{\circ}$ respectively, the relative azimuth angle is equal to $0^{\circ}$. We also calculated the TOA reflectance at $3.7 \mu \mathrm{m}$ for the same conditions. The difference between the simulated TOA reflectance at $3.7 \mu \mathrm{m}$ and the one reconstructed from the BT using Eq. (10) is shown in Fig. 5 for the both viewing geometries. The color filled areas represent the error in the reconstructed TOA reflectance at 3.7 $\mu \mathrm{m}$, which occurs due to calibration error of AATSR BT product of $\pm 0.1 \mathrm{~K}$. The relative error of such a reconstruction is around $1 \%$ for the forward view and around $12 \%$ for the nadir view, which appears to be reasonable as the nadir view reflectance has much smaller order of magnitude in comparison to the forward view reflectance.

Then, these reconstructed TOA reflectances at $3.7 \mu \mathrm{m}$ were used for the AOT retrieval according to Eq. (10). The relative error of the retrieved AOT depending on the input AOTs is shown in Fig. 6. Again, the color filled areas represent the error in the retrieved AOT which occurs due to the calibration 


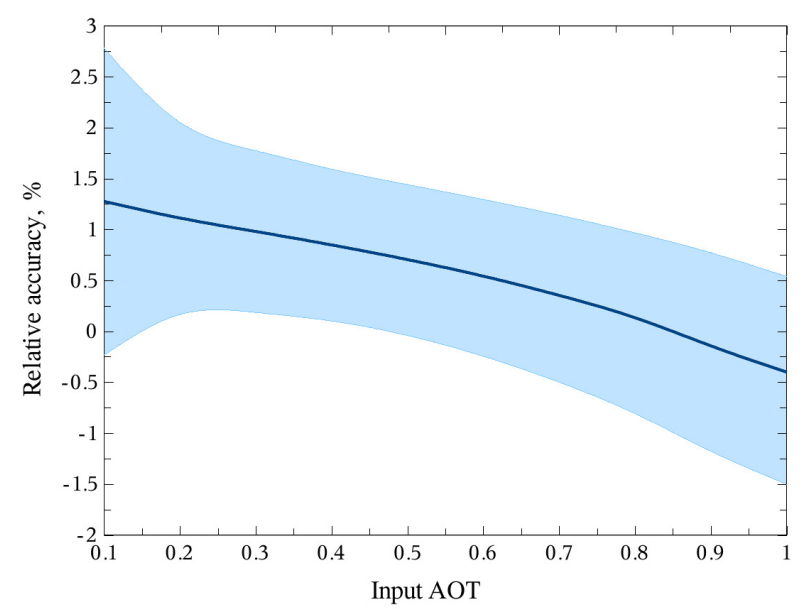

Fig. 6. The relative error of the retrieved AOT for a given input AOT (blue line). The color filled area shows the sensitivity of the retrieved AOT to the AATSR BT calibration error of $\pm 0.1 \mathrm{~K}$.

error in AATSR BT product of $\pm 0.1 \mathrm{~K}$. As our simulations did not include any surface, the simulated retrieval was performed without the surface correction introduced in Eq. (12). The simulation shows that the sensitivity of retrieved AOT to the AATSR BT calibration error of $\pm 0.1 \mathrm{~K}$ is around several percent.

\subsection{Calculation of LUTs for Arctic conditions}

Unlike e.g. Rayleigh scattering, the phase function of which is well known, aerosol reflectance $\rho_{\mathrm{aer}}\left(\lambda, \mu_{0}, \mu, \phi\right)$ is variable due to different particle size distribution, particle shape and chemical composition, which affects single scattering albedo and extinction of aerosol layer. All this makes aerosol reflectance highly dependent on illumination-observation geometry and variable from one aerosol type to another. This makes it impossible to create one atmospheric LUT, which would represent aerosol properties well on global scale. As current work is dedicated to AOT retrieval in Arctic region, we took the advantage of ground based aerosol measurements and created a LUT using phase function and single scattering albedo values measured in situ during one of the regular pollution events in Arctic (Treffeisen et al., 2007; Stohl et al., 2007). It has been measured on 23 March 2000 at Spitsbergen, Ny Ålesund, Svalbard, $78.923^{\circ} \mathrm{N} 11.923^{\circ} \mathrm{E}$, by the Alfred Wegener Institute for Polar and Marine Research at $867 \mathrm{~nm}$. The AOT at $500 \mathrm{~nm}$ was around 0.15 , single scattering albedo 0.74 with the average Angström alpha equal to 1.46. This phase function is shown in Fig. 7. One can see the clear resemblance of this phase function to the IR phase functions in Fig. 1, despite of the much shorter wavelength. The LUT has been calculated for a variety of illumination geometries (solar zenith angle from $35^{\circ}$ to $85^{\circ}$ with the step of $10^{\circ}$ ), observation geometries (viewing zenith angle from $0^{\circ}$ to $90^{\circ}$ with the step of $10^{\circ}$ ) and relative azimuth angles (from

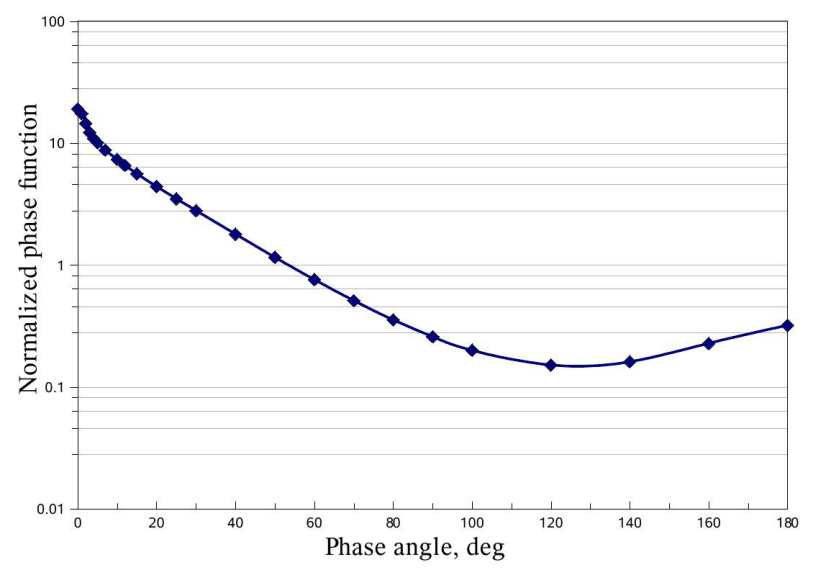

Fig. 7. The phase function of Arctic haze measured on 23 March 2000 during one of the regular haze events at Spitsbergen, Ny Ålesund, Svalbard, $78.923^{\circ} \mathrm{N} 11.923^{\circ} \mathrm{E}$, by the Alfred Wegener Institute for Polar and Marine Research at $867 \mathrm{~nm}$.

$0^{\circ}$ to $180^{\circ}$ with the step of $12^{\circ}$ ). The AOT range was from 0 to 1 (at $500 \mathrm{~nm}$ ). The LUT has been calculated with the single scattering albedo equal to 0.90 at $500 \mathrm{~nm}$ and 0.71 at $3.7 \mu \mathrm{m}$, which corresponds to the accumulation mode of the dust-like aerosol (see Tables 1 and 2). It is important to note that the current phase function corresponds to a certain particle size distribution (Angström alpha value of 1.46). While this spectral slope of aerosol is quite common (as seen from AERONET data for Arctic stations), larger or smaller particles can cause large scatter of the reflectance data, which would cause similar scatter in the retrieved AOTs. This scatter can be reduced only with aerosol-type sensitive retrieval, which requires multispectral observations. Over snow this task is quite challenging and will be solved in the next versions of the retrieval.

\section{Validation of the aerosol optical thickness retrieval}

The algorithm has been validated against AERONET measurements for the four high Arctic stations. The stations have been chosen to feature frequent AATSR overflights and therefore provide statistically significant amount of data. These stations are OPAL $\left(79^{\circ} 59^{\prime} 24^{\prime \prime} \mathrm{N}, 85^{\circ} 56^{\prime} 20^{\prime \prime} \mathrm{W}\right.$, altitude $0 \mathrm{~m})$, PEARL $\left(80^{\circ} 03^{\prime} 14^{\prime \prime} \mathrm{N}, 86^{\circ} 25^{\prime} 01^{\prime \prime} \mathrm{W}\right.$, altitude $615 \mathrm{~m})$, Thule $\left(76^{\circ} 30^{\prime} 57^{\prime \prime} \mathrm{N}, 68^{\circ} 46^{\prime} 08^{\prime \prime} \mathrm{W}\right.$, altitude $225 \mathrm{~m}$ ), Kangerlussuaq ( $66^{\circ} 59^{\prime} 45^{\prime \prime} \mathrm{N}, 50^{\circ} 37^{\prime} 15^{\prime \prime} \mathrm{W}$, altitude $320 \mathrm{~m}$ ). All these stations provide relatively continuous and long datasets of ground based data, however they are located in the areas of complicated terrain. The first three stations are standing at the fjords of Queen Elisabeth Islands and Knud Rasmussen Land, and the last one is located at W-Greenland about $200 \mathrm{~km}$ from the coast. None of these stations are located on a permanently snow covered terrain, and depending on season they feature different surface types, from clear 


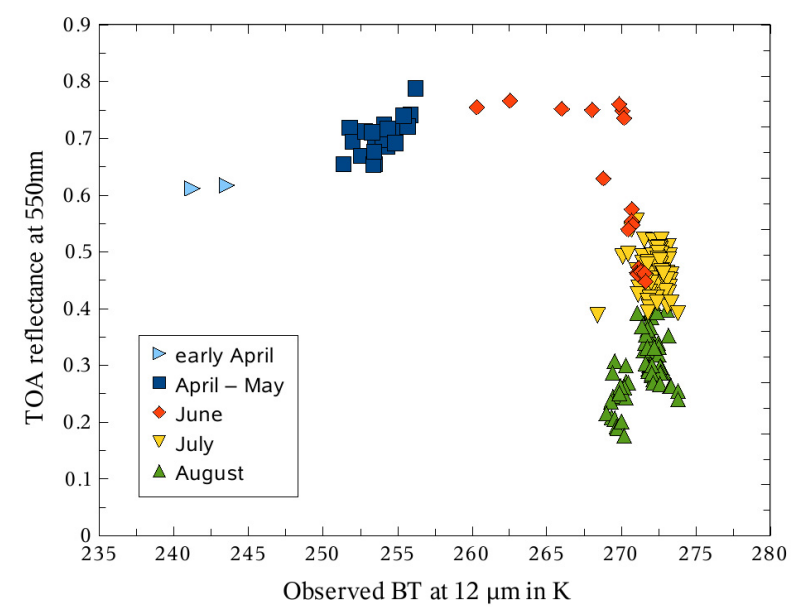

Fig. 8. Analysis of the validation dataset for station OPAL which contains nearly 200 points spring and summer of years 2007-2009. Only cloud free snow flagged data were taken into account. The dependence of TOA reflectance at $550 \mathrm{~nm}$ on BT at $12 \mu \mathrm{m}$ shows the evolution of surface type with the time of the year. Most of the dataset represents melting sea ice surface type (summer months), whereas data from April and May represent ice covered with snow.

snow in spring to bare soil and rocks in late summer and autumn. To avoid losing vast majority of the validation data, for each of the station we have chosen a position within $1 \mathrm{de}-$ gree of longitude and 0.5 degree of latitude located on permanent snow cover (for Greenland) or on the sea ice (for Queen Elisabeth Islands). This allows us to shift from snow/bare soil/rocks mixture (which is screened out due to very little snow part) to melting sea ice (which is generally darker than snow but still keeps most of snow properties and is not screened out). On this basis the performance of the retrieval for various surface types, both snow and sea ice was tested under different conditions. This is illustrated by an analysis of the validation dataset for e.g. station OPAL (see Fig. 8). It shows that most of the dataset points come from summer months and feature quite low TOA reflectance at $550 \mathrm{~nm}$ together with quite high surface temperatures (yet below $0{ }^{\circ} \mathrm{C}$ ). As these data have been cloud cleared and snow flagged, the low TOA reflectance suggests the surface type "melting sea ice without snow cover". Spring data, however, shows low temperatures and high TOA reflectances at $550 \mathrm{~nm}$, which is an evidence of "snow covered sea ice". AOT retrieval is possible over both of these surface types.

Our validation dataset for stations PEARL contain approximately 200 points and for station OPAL 130 points from spring and summer of years 2007, 2008, 2009. Stations Thule and Kangerlussuaq gave less cloud free observations overlapping with AATSR overflights - around 40 points from years 2007 and 2008 for Thule, and 20 points from years 2008 and 2009 for Kangerlussuaq.

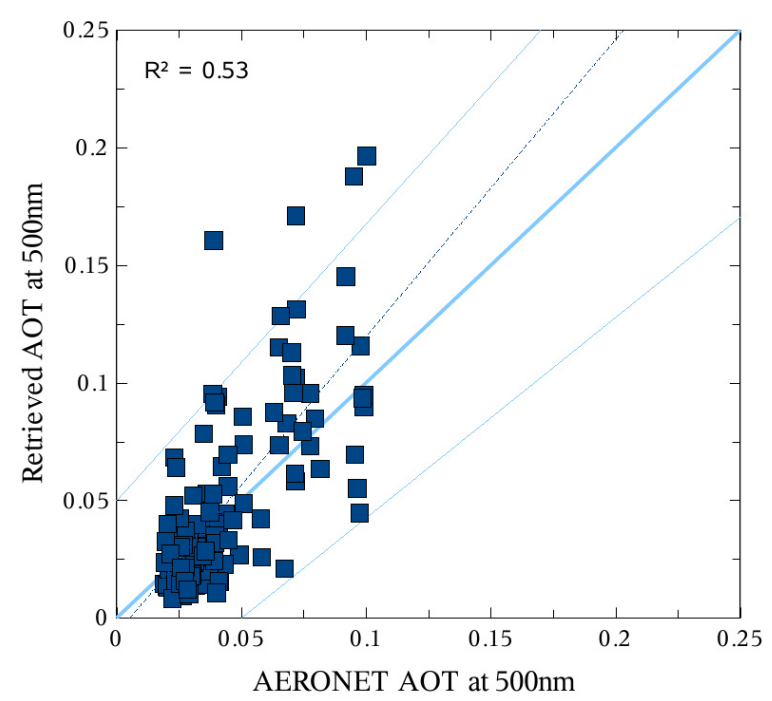

Fig. 9. Comparison of the retrieved AOTs derived from AATSR product as $3.7 \mu \mathrm{m}$ and AERONET AOTS for station OPAL. The dashed line represents the linear regression of the data. $\mathrm{RMSD}=0.0283, R^{2}=0.53$.

All the data has been cloud screened and snow flagged. AERONET data with extreme values of Angström coefficient for $440-870 \mathrm{~nm}$ (less than 0.5 and more than 2.0) were not taken into account. The maximum allowed time difference between the AATSR overflight and the AERONET measurement was equal to $15 \mathrm{~min}$. We applied spatial averaging of the AATSR data within 0.1 degree of latitude and 1 degree of longitude. The range of sun zenith angles of the entire validation dataset is from approximately $55^{\circ}$ to $75^{\circ}$, with the vast majority of the values around $60^{\circ}$. Average relative azimuth angle is approximately $30^{\circ}$. As AERONET gives the best temporal coverage at $500 \mathrm{~nm}$, the comparison has to be performed at this wavelength. To estimate the AOT at $500 \mathrm{~nm}$ with the retrieval which utilizes AATSR channel at $3.7 \mu \mathrm{m}$, we use a fixed Angström parameter equal to 1.0. The correlation plot for each station is showed in Fig. 9 (OPAL), Fig. 10 (PEARL), Fig. 11 (Thule), Fig. 12 (Kangerlussuaq). The dashed line represents the linear regression of the data.

It is visible that each of the correlation plots shows a larger scatter in the retrieved AOTs, the larger the AERONET AOT is. This is explained by a greater effect of the aerosol type and its spectral slope for larger AOT values. As the values of AERONET Angström coefficient for 440-870 nm are ranging from 0.5 to 2.0, and our LUT has been created for 1.0 only, this large scatter is expected and will be corrected in the next version of the algorithm. At AOTs less than 0.1 the retrieval works satisfactory with no significant over- or underestimation. As the vast majority of AOT values in the Arctic are below 0.1, the retrieved AOT maps can give a good estimate of the AOT distribution over snow. 


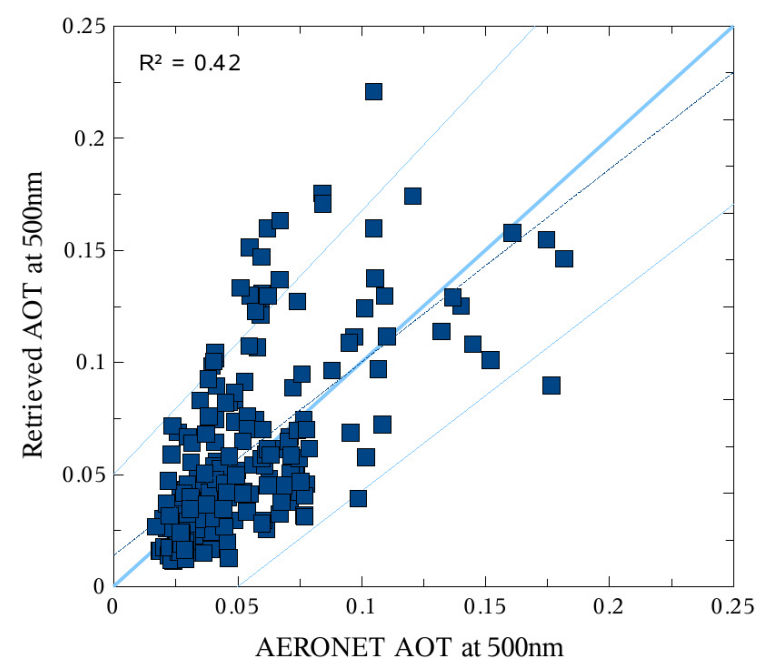

Fig. 10. Comparison of the retrieved AOTs derived from AATSR product as $3.7 \mu \mathrm{m}$ and AERONET AOTS for station PEARL. The dashed line represents the linear regression of the data. $\mathrm{RMSD}=0.0329, R^{2}=0.42$.

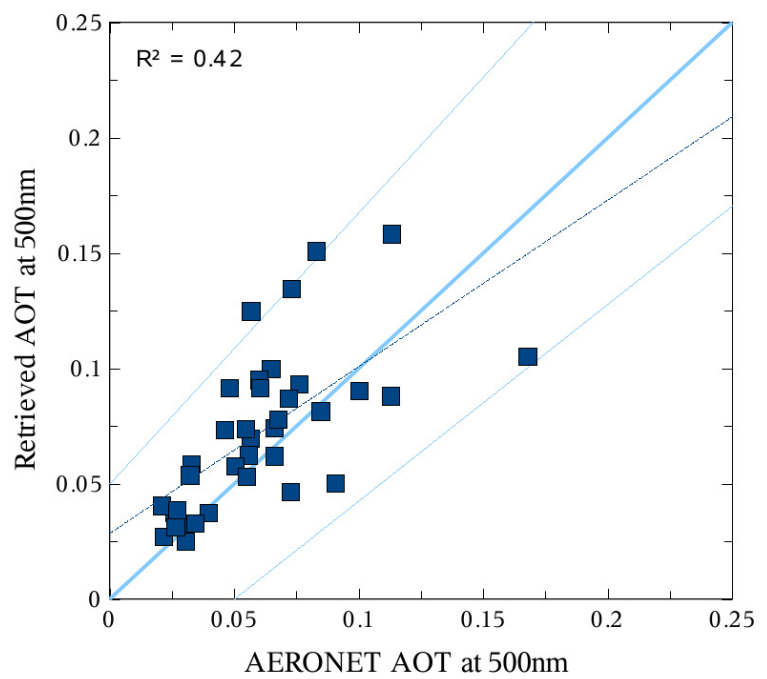

Fig. 11. Comparison of the retrieved AOTs derived from AATSR product as $3.7 \mu \mathrm{m}$ and AERONET AOTS for station Thule. The dashed line represents the linear regression of the data. $\mathrm{RMSD}=0.0293, R^{2}=0.42$.

\section{Case study: dust formation and transport on Greenland during 4-5 July 2008}

A noticeable dust event has been observed on the 4 July 2008, in the vicinity of Kangerlussuaq, W-Greenland. The dust event was triggered by a northeasterly wind breezing up during the morning and mobilising mineral dust from open soils along the Søndre Strømfjord (see Fig. 13). The dust cloud developed during the morning of a clear, sunny day.

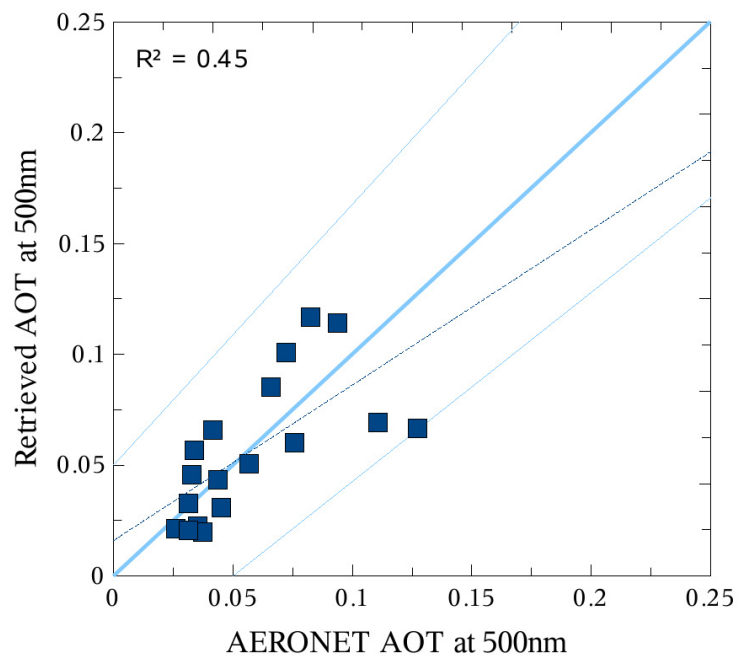

Fig. 12. Comparison of the retrieved AOTs derived from AATSR product as $3.7 \mu \mathrm{m}$ and AERONET AOTS for station Kangerlussuaq. The solid line represents the linear regression of the data. $\mathrm{RMSD}=0.0289, R^{2}=0.45$.

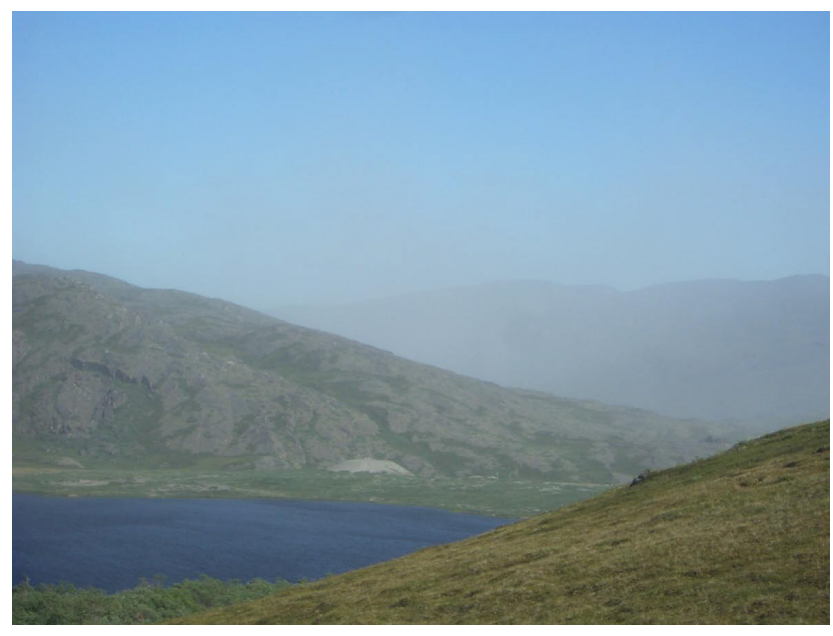

Fig. 13. A dust event has been observed at Greenland on 4 July 2008 near Kangerlussuaq, where strong winds mobilized mineral particles from areas of open land. The horizontal visibility as estimated by witnesses was around $10 \mathrm{~km}$.

The maximum occurred in the early afternoon and gradually declined with decreasing wind speed in late afternoon. Maximum temperature was $22^{\circ} \mathrm{C}$ on this day. The relative air humidity during the day ranged below $35 \%$. The dust cloud was observed about $15 \mathrm{~km}$ west of Kangerlussuaq reducing horizontal visibility down to about $10 \mathrm{~km}$. The dust layer vertically grew during the day with increasing wind speed, reaching a maximal thickness of estimated $500 \mathrm{~m}$ above ground at early afternoon. 

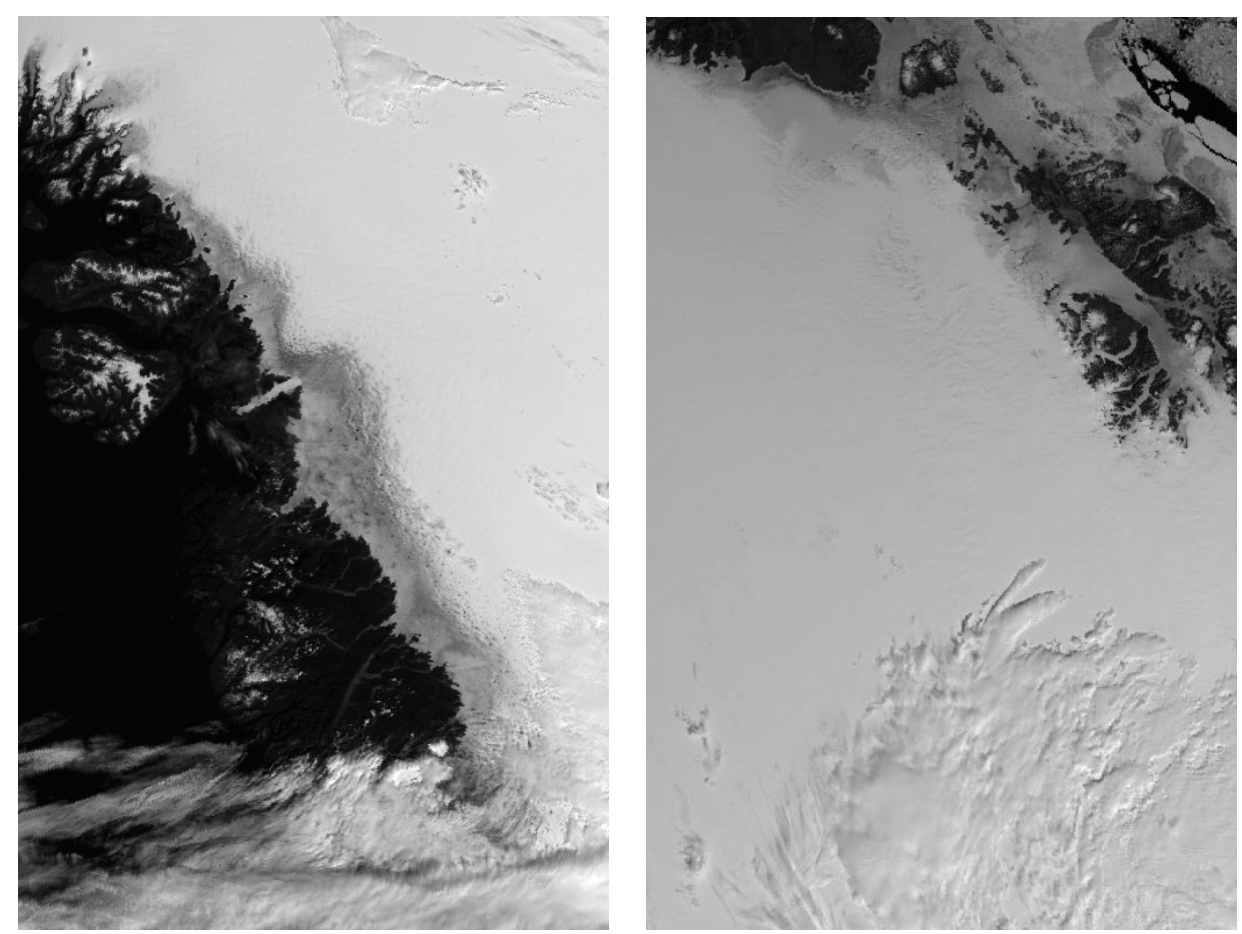

Fig. 14. AATSR nadir view reflectances at $550 \mathrm{~nm}$ for the area near Kangerlussuaq (left panel) and for the NE-Greenland (right panel). Neither of them shows signs of aerosol pollution.

The following day, 5 July, was clear again but showed only weak winds. As expected no dust mobilisation was observed. However, a katabatic wind of a limited range was experienced when approaching the ice sheet, but this wind did not reach highly erodible periglacial landforms downslope the fjord. Those landforms comprising sandar, terraces, moraines, banks of braided streams or dunes act as particular source areas of coarse mineral dust

The visible particle transport by katabatic winds in the Søndre Strømfjord can be assumed as part of a circulation system including a downstream flow at ground level and an upstream flow at higher elevations. The downstream wind can be supposed governing the particle transport near the surface away from the ice sheet. Still unknown is the question to what extent mobilized particles are able to raise up during transport possibly due to turbulent mixing and thereby reaching the opposite directed flow at higher elevation. In this case at least the finer fraction of windblown particles (2$3 \mu \mathrm{m}$ ) may be transported backwards towards the ice sheet. Near Kangerlussuaq, W-Greenland, the existence of such a backflow was confirmed by balloon measurements of Oerlemans and Vugts (1993) and by investigation flights of Heinemann (1999). By these authors, the backflow was found ranging between $150 \mathrm{~m}$ (Oerlemans and Vugts, 1993) and 1000 m a.g.l. (Heinemann, 1999),

The above mentioned dust cloud originating on 4 July was expected to significantly raise AOT. This enhanced AOT should allow us to detect the dust cloud by using a variation of the Koschmieder equation suggested by Bäumer et al. (2008). The equation can be written as follows:

$V=3.912 z \tau^{-1}$

where $V$ is the horizontal visibility, $z$ is the height of the pollution layer, $\tau$ is the AOT at $550 \mathrm{~nm}$. For above mentioned parameters of the pollution event, AOT takes a value of approximately 0.4 .

For the satellite retrieval we used the AATSR overflight on 5 July 2008, $14 \mathrm{~h} 46 \mathrm{~min} 02 \mathrm{~s}$, and orbit 1 number 33187. The map of retrieved AOTs is shown in Fig. 14, left panel. Arrows show increased AOT east of Kangerlussuaq (left bottom corner), and on the opposite side of Greenland (right upper corner), where the same mechanism of dust mobilization is supposed. AATSR reflectances at visible wavelengths do not show any evidence of the increased aerosol load or different surface type at these points (see Fig. 14, left panel for location near Kangerlussuaq and right panel for the opposite shore of Greenland). It is visible that the retrieved AOTs (Fig. 15, left panel) resemble the same pattern as calculated TOA reflectances at $3.7 \mu \mathrm{m}$ (Fig. 15, right panel).

Figure 16 shows the map of retrieved AOT over Greenland after the discussed dust event, on 15 July 2008, $14 \mathrm{~h} 32 \mathrm{~min}$ $18 \mathrm{~s}$, orbit number 33330. No evidence of pollution is visible in the Kangerlussuaq area, which proves that the increase of AOT near Kangerlussuaq on 5 July 2008 visible in the retrieved AOT map is not a surface feature, but an atmospheric pollution. 

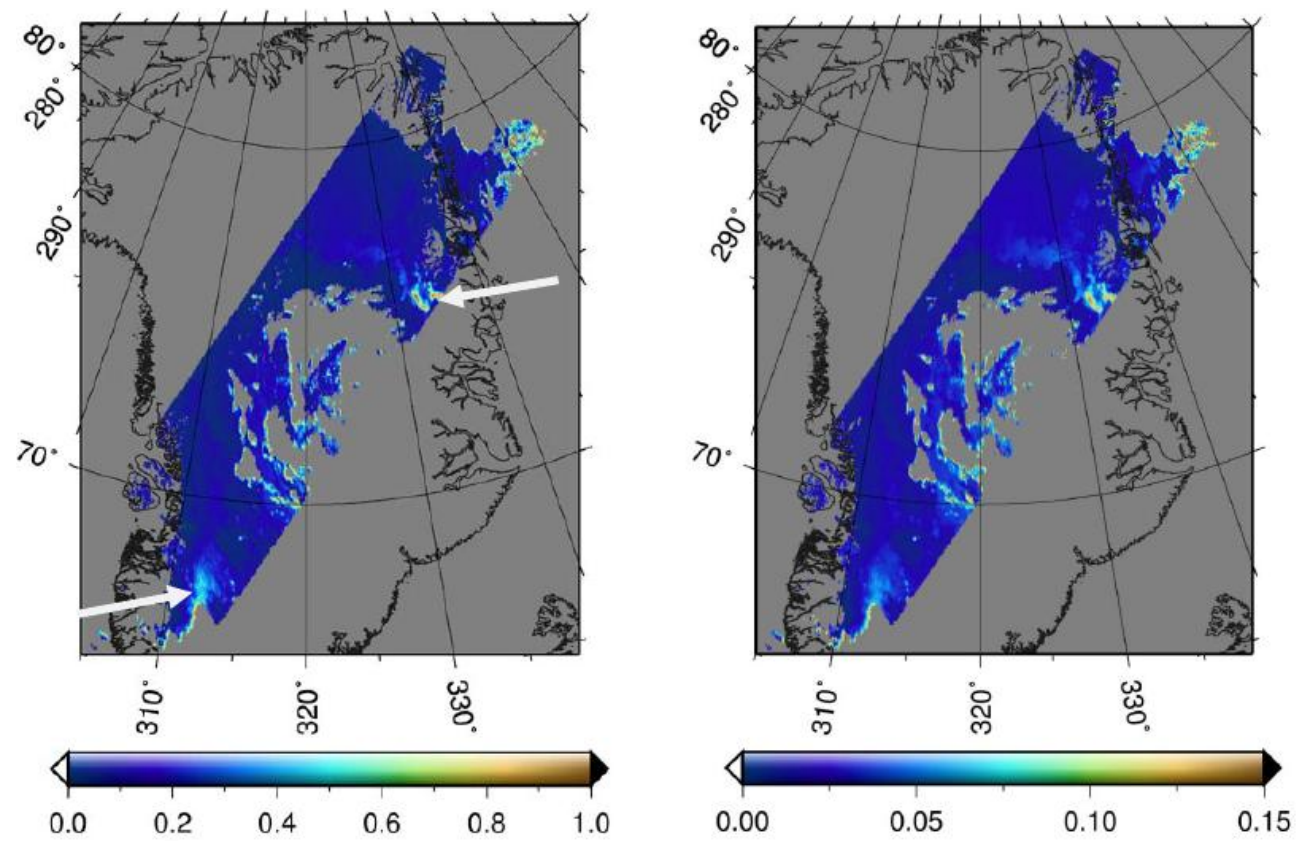

Fig. 15. The map of retrieved AOT over Greenland on 5 July 2008, 14 h 46 min 02 s, orbit number 33187 (left panel). Arrows indicate increased AOT near Kangerlussuaq (left bottom corner), where a dust event has been observed on 4 July 2008 (see Fig. 13), and on the NE-Greenland (right upper corner), where the same mechanism of dust mobilization is expected. The $3.7 \mu \mathrm{m}$ reflectance map of the same scene (right panel) shows the same pattern as the AOT.

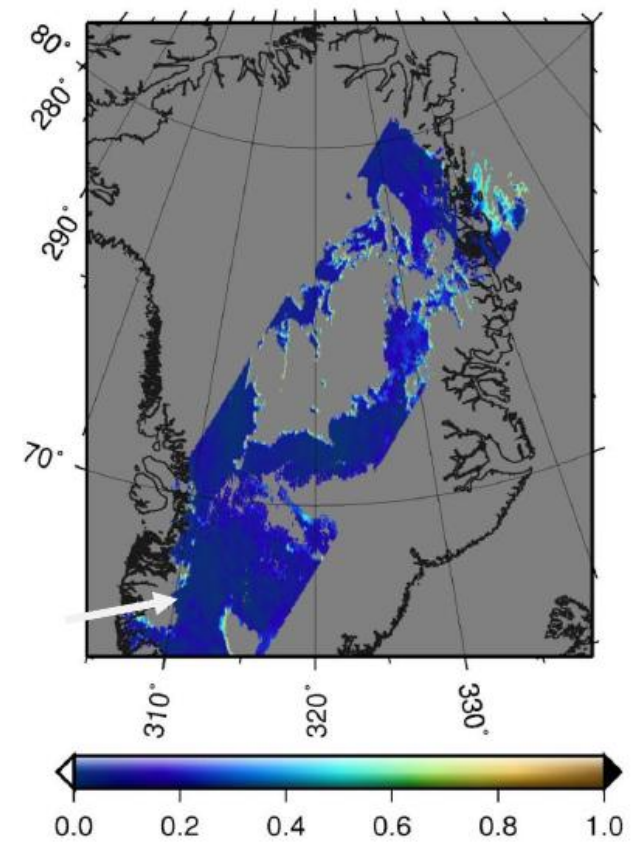

Fig. 16. The map of retrieved AOT over Greenland after the discussed dust event, on 15 July 2008, 14 h 32 min 18 s, orbit number 33330. No evidence of pollution is visible in the Kangerlussuaq area (shown with the arrow).
Despite of the obvious mineral dust cloud shown in Fig. 13 with an AOT $(500 \mathrm{~nm})$ of 0.028 and an Angström exponent (440-870) around 0.8, AERONET station Kangerlussuaq $\left(66^{\circ} 59^{\prime} 45^{\prime \prime} \mathrm{N}, 50^{\circ} 37^{\prime} 15^{\prime \prime} \mathrm{W}\right)$ shows no evidence of a dust event neither on 4 July nor on 5 July. This discrepancy is possibly explainable by a non-uniform dust layer of very coarse particles. Due to the inhomogeneous structure and local flow dynamics, the AERONET instrument was not able to detect the higher particle concentrations at its specific location.

\section{Conclusions}

In current work we performed a comprehensive analysis of aerosol scattering characteristics at $3.7 \mu \mathrm{m}$ using RT calculations to simulate TOA reflectance and phase functions for coarse and accumulation modes of four main aerosol components. Strong angular dependence of aerosol IR reflectance makes it possible to retrieve AOT of these particles at $3.7 \mu \mathrm{m}$ at some non-nadir angles. At the same time, aerosol reflectance is low for the nadir observation geometry, which allows us to use AATSR nadir observations at this wavelength for surface correction. Performed sensitivity study showed that AATSR IR calibration error would affect the resulting AOT within the range of several percent. Therefore the formerly known method of inverting the Planck function in order to extract the reflectance part from the BT product can be 
used for the AOT retrieval over snow. A simple LUT-based algorithm similar to traditional AOT retrievals over ocean is used to retrieve AOT over snow using calculated TOA reflectances at $3.7 \mu \mathrm{m}$. It has been validated against 4 high Arctic AERONET stations and shows good agreement with no systematic over- or underestimation for small AOT values below 0.1 .

Therefore the presented retrieval can be used for AOT retrieval over snow in order to study the details of aerosol distribution and transport in Arctic at least at a qualitative level.

We expect the uncertainty of the retrieval to grow for the larger AOTs due to larger effect of aerosol spectral slope on such values. This can be solved with an aerosol type sensitive retrieval, which should make use of several AATSR spectral channels and will be implemented in the next version of the retrieval.

A case study was performed for the dust event observed on 4 July 2008 along the Søndre Strømfjord (Kangerlussuaq) on W-Greenland. Fresh winds mobilized mineral dust from bare soil areas on that day. On 5 July the retrieved AOT map still shows an obvious increase of AOT east of Kangerlussaq. The upstream position is explained by a small scale circulation transporting the mobilized dust in direction ice sheet by its upper branch. The retrieval also shows increased AOT on NE-Greenland. A similar mechanism of dust transport can be assumed to explain this so far unconfirmed dust event also occurring in the vicinity of a bare soil area. However, the assumed particle transport has to be confirmed by vertical and horizontal aerosol measurement at the margin of the ice sheet in order to confirm the supposed transport of local mineral dust onto the ice sheet.

Acknowledgements. The authors are grateful to ESA for providing AATSR data, to R. Treffeisen and M. Stock for providing their aerosol phase function measurements, to V. Rozanov and A. Rozanov for the help with the forward RT model SCIATRAN, to M. Mishchenko for providing the Lorenz-Mie code. We thank Norm O'Neill and Brent Holben for their effort in establishing and maintaining AERONET sites PEARL, OPAL, Thule, Kangerlussuaq.

Edited by: P. K. Bhartia

\section{References}

Allen, R. C., Durkee, P. A., and Wash, C. H.: Snow/cloud discrimination with multispectral satellite measurements, J. Appl. Meteor., 29, 994-1004, 1990.

Bäumer, D., Vogel, B., Versick, S., Rinke, R., Mohler, O., and Schnaiter, M.: Relationship of visibility, aerosol optical thickness and aerosol size distribution in an ageing air mass over South-West Germany, Atmos. Environ., 42(5), 989-998, doi:10.1016/j.atmosenv.2007.10.017, 2008.

De Rooij, W. A. and Van der Stap, C. C. A. H.: Expansion of Mie scattering matrices in generalized spherical functions, Astron. Astrophys., 131, 237-248, 1984.
English, S. J., Jones, D. C., Hewison, T. J., Saunders, R. W., and Hallikainen, M.: Observations of the emissivity of snow and ice surfaces from the SAAMEX and MACSI airborne campaigns, Geoscience and Remote Sensing Symposium, 1995, IGARSS '95, Quantitative Remote sensing for Science and Applications, International, vol. 2, 14930-1495, 1995.

Heinemann, G.: The KABEG'97 field experiment: an aircraft based study of the katabatic wind dynamics over the Greenlandic ice sheet, Bound.-Lay. Meteorol. 93, 75-116, 1999.

Hobbs, P.: Aerosol-Climate-Cloud Interations. Academic Press Inc., 240 pp., 1993.

Hori, M., Aoki, Te., Tanikawa, T., Motoyoshi, H., Hachikubo, A., Sugiura, K., Yasunari, T.J., Eide, H., Storvold, R., Nakajima, Y., and Takahashi, F.: In-situ measured spectral directional emissivity of snow and ice in the 8-14 um atmospheric window, Remote Sens. Environ., 100, 486-502, 2006.

Istomina, L. G., von Hoyningen-Huene, W., Kokhanovsky, A. A., Rozanov, V. V., Schreier, M., Dethloff, K., Stock, M., Treffeisen, R., Herber, A., and Burrows, J. P.: Sensitivity study of the dualview algorithm for aerosol optical thickness retrieval over snow and ice, Proceedings of the 2nd MERIS/(A)ATSR user workshop, ESRIN, Frascati, Italy, 22-26 Sept. 2008, ESA SP-666, 2009.

Istomina, L. G., von Hoyningen-Huene, W., Kokhanovsky, A. A., and Burrows, J. P.: Retrieval of aerosol optical thickness in Arctic region using dual-view AATSR observations. Proceedings of ESA Atmospheric Science Conference, Barcelona, Spain, 0711 Sept. 2009. ESA SP-676, 2010a.

Istomina, L. G., von Hoyningen-Huene, W., Kokhanovsky, A. A., and Burrows, J. P.: The detection of cloud-free snow-covered areas using AATSR measurements, Atmos. Meas. Tech., 3, 10051017, doi:10.5194/amt-3-1005-2010, 2010b.

Kasten, F. and Young, A. T.: Revised optical air mass tables and approximation formula, Appl. Optics, 28(22), 4735-4738, 1989.

Kokhanovsky, A. A.: Light Scattering Media Optics: Problems and Solutions, Chichester, Springer-Praxis Books in Environmental Sciences, 3rd Edn., 2004.

Mishchenko, M. I., Dlugach, J. M., Yanovitskij, E. G., and Zakharova, N. T.: Bidirectional reflectance of flat, optically thick particulate layers: an efficient radiative transfer solution and applications to snow and soil surfaces, J. Quant. Spectrosc. Radiat. Transfer, 63, 409-432, 1999.

Oerlemans, J. and Vugts, H. F.: A meteorological experiment in the melting zone of the Greenland ice sheet, B. Am. Meteorol. Soc., 74, 355-365, 1993.

Rees, W. G.: Remote Sensing of Snow and Ice, Taylor \& Francis, 312 pp., 2006.

Rozanov, A. V., Rozanov, V. V., Buchwitz, M., Kokhanovsky, A. A., and Burrows, J. P.: SCIATRAN 2.0 - new radiative transfer model for geophysical applications in the $175-2400 \mathrm{~nm}$ spectral range, Adv. Space Res. 36, 1015-1019, 2005.

Smith, D. L., Delderfield, J., Drummond, D., Edwards, T., Mutlow, C. T., Read, P. D., and Toplis, G. M.: Calibration of the AATSR instrument, Adv. Space Res., 28(1), 31-39, 2001.

Spangenberg, D. A., Chakrapani, V., Doelling, D. R., Minnis, P., and Arduini, R. F.: Development of an automated Arctic cloud mask using clear-sky satellite observations taken over the SHEBA and ARM NSA sites, Proc. 6th Conf. on Polar Meteor. and Oceanography, San Diego, CA, May 14-18, 2001, 246- 
249, 2001.

Stohl, A., Berg, T., Burkhart, J. F., Fjǽaeraa, A. M., Forster, C., Herber, A., Hov, Ø., Lunder, C., McMillan, W. W., Oltmans, S., Shiobara, M., Simpson, D., Solberg, S., Stebel, K., Ström, J., Tørseth, K., Treffeisen, R., Virkkunen, K., and Yttri, K. E.: Arctic smoke - record high air pollution levels in the European Arctic due to agricultural fires in Eastern Europe in spring 2006, Atmos. Chem. Phys., 7, 511-534, doi:10.5194/acp-7-511-2007, 2007.

Tomasi, C., Vitale, V., Lupi, A., Di Carmine, C., Campanelli, M., Herber, A., Treffeisen, R., Stone, R. S., Andrews, E., Sharma, S., Radionov, V., von Hoyningen-Huene, W., Stebel, K., Hansen, G. H., Myhre, C. L., Wehrli, C., Aaltonen, V., Lihavainen, H., Virkkula, A., Hillamo, R., Ström, J., Toledano, C., Cachorro, V. E., Ortiz, P., de Frutos, A. M., Blindheim, S., Frioud, M., Gausa, M., Zielinski, T., Petelski, T., and Yamanouchi, T.: Aerosols in polar regions: A historical overview based on optical depth and in situ observations, J. Geophys. Res., 112, D16205, doi:10.1029/2007JD008432, 2007.
Treffeisen, R., Tunved, P., Ström, J., Herber, A., Bareiss, J., Helbig, A., Stone, R. S., Hoyningen-Huene, W., Krejci, R., Stohl, A., and Neuber, R.: Arctic smoke -aerosol characteristics during a record smoke event in the European Arctic and its radiative impact, Atmos. Chem. Phys., 7, 3035-3053, doi:10.5194/acp-73035-2007, 2007.

Trepte, Q., Chen, Y., Sun-Mack, S., Minnis, P., Young, D. F., Baum, B. A., and Heck, P. W.: Scene identification for the CERES cloud analysis subsystem. Proc. AMS 10th Conf. Atmos. Rad., Madison, WI, 28 June-2 July, 169-172, 1999.

Twomey S.: Atmospheric Aerosols. Elsevier Scientific Pub., 302 pp., 1997.

Wald, A. E.: Modeling thermal infrared (2-14 $\mu \mathrm{m})$ reflectance spectra of frost and snow, J. Geophys. Res., 99(B12), 24241-24250, 1994. 